\title{
INOVAÇÃO E SUA PRINCIPAL BARREIRA JURÍDICA
}

\author{
INNOVATION AND YOUR MAIN LEGAL BARRIER
}

\section{INNOVACIÓN Y SU PRINCIPAL BARRERA JURÍDICA}

\author{
https://orcid org/0000-0002-2834-6324 / http://lattes.cnpq br/9554142049617388 / chiarello felipe@gmail.com \\ Universidade Presbiteriana Mackenzie - MACKENZIE \\ São Paulo, SP - Brasil. \\ LARA ROCHA GARCIA \\ https://orcid.org/0000-0001-7329-1134 / http://lattes.cnpq.br/2261897624350085 / lararochagarcia@gmail.com \\ Universidade Presbiteriana Mackenzie - MACKENZIE \\ São Paulo, SP - Brasil.
}

Felipe Chiarello de Souza Pinto

\begin{abstract}
RESUMO
O presente artigo, fundamentalmente no campo do Direito da Inovação e do Direito Econômico, tem o objetivo de analisar se o Sistema Nacional de Ciência e Inovação oferece suporte jurídico para a transformação que a tecnologia está realizando nos diversos mercados, inclusive, na própria prática jurídica. Foi realizada pesquisa qualitativa para descrever o Sistema Nacional de Ciência e Inovação e, com isso, compreender o ecossistema de inovação brasileiro com vistas a fomentar o desenvolvimento econômico nacional. A partir deste panorama, foi utilizado o método dedutivo para aplicar a inovação, especialmente de base tecnológica, à prática jurídica em si, com a proliferação das startups chamadas de lawtechs e legaltechs. Assim, é apresentado a estruturação e o contraste dos desafios e barreiras do Direito da Inovação e da Inovação no Direito. A conclusão deste artigo é a de que o Direito, seus profissionais, estrutura de atuação, hierarquia e até mesmo os novos modelos de negócio que surgem a partir da inovação de base tecnológica serão fortemente impactados pelo potencial das inovações de base tecnológica assim como pelo arcabouço do Sistema Nacional de Ciência e Inovação, especialmente pela Lei Geral de Proteção de Dados Pessoais. Isso porque dependem, essencialmente, da captura de dados, tratamento e análise para gerar informação relevante na prestação de serviços. Embora tal lei esteja ainda em vacatio legis e não temos sua aplicabilidade pratica, não exclui a discussão, que deve ser realizada a partir de análises críticas.
\end{abstract}

Palavras-chave: direito digital; inovação; proteção de dados; startups; tecnologia.

\begin{abstract}
This article, based on Innovation Law and Economic Law fields, aim to discuss if "Sistema Nacional de Ciência e Inovação" supports the transformation that technology is performing in many markets, including, in Law. It was used qualitative research to describe "Sistema Nacional de Ciência e Inovação" and to comprise Brazilian innovation ecossystem, which aims to develop national economy. From this perspective, was used deductive methodology to apply innovation specially technology-based ones in the legal practice itself, with the widespread of lawtechs and legaltechs. In this way, is introduced and contrasted the challenges and barriers of Innovation Law and Innovation in Law. The conclusion is that law itself, its professionals, structure, hierarchy and even new business models that emerges from technology innovation will be impacted specially by Brazilian General Data Protection Regulation due to their dependency, essentially, of data capture, treatment and analysis to generate relevant information in law service. This article ignites a discussion considering that this law still is in vacatio legis and there is no practical applicability yet.
\end{abstract}

Keywords: data protection; economic law; innovation; legaltech; technology; startups.

\section{RESUMEN}

El presente artículo, fundamentalmente en el campo del Derecho de la Innovación y el de Derecho Económico, tiene el objetivo de pesquisar se el "Sistema Nacional de Ciencia e Inovação" suporta jurídicamente la transformación que 
la tecnología está a realizar en los diversos mercados, incluyendo, la propia práctica jurídica. La metodología utilizada fue la hipotética-deductiva bajo la luz de los marcos teóricos presentados, que objetiva verificar la dificultad del derecho para solucionar los cambios trajimos por la innovación, especialmente de base tecnológica, en los diferentes mercados, con el aumento de las startups conocidas como lawtechs y legaltechs. La conclusión de lo artículo es de que el Desecho, sus profesionales, estructura de actuación, jerarquía y até mismo los nuevos modelos de negocio que surgen a partir de la innovación de base tecnológica, van a ser fuertemente impactados pelo contorno del "Sistema Nacional de Ciência e Inovação", especialmente por la Leí Geral de Proteção de Dados Pessoais. Eso ocurre depende, en la esencia, de la captura de los dados, tratamiento y análisis para generar información relevante na prestación de servicios. Aunque tal leí este en vacatio legis y no ha aplicabilidad práctica, no excluín la discusión, que debe ser realizada a partir de análisis criticas.

Palabras clave: protección de dados; derecho económico; innovación; tecnología; empreendedorismo.

\section{SUMÁRIO}

INTRODUCAO; 1 POR QUE FAZER INOVAÇÃO? 2 QUEM FAZ INOVAÇÃO NO BRASIL; 3 INOVAÇÃO NO DIREITO: IMPACTO DAS LEGALTECHS NA PRÁTICA JURÍDICA; CONCLUSÃO; REFERÊNCIAS.

\section{INTRODUÇÃO}

A inovação pode ser uma alavanca de desenvolvimento econômico nacional se fomentada com o propósito final de estimular a economia. Nesse sentido, o Direito Econômico e o Direito da Inovação deveriam ter como objetivo garantir segurança jurídica para que inventores, inovadores e empreendedores possam se arriscar, desde a constituição até legislação infraconstitucional específica, como o Marco Legal da Inovação, principal diploma sobre o tema, a Lei de Proteção de Dados Pessoais e o Marco Civil da Internet, entre outros.

Saber os diferentes papéis na engrenagem da inovação, seus incentivos e interesses ajuda a entender se o arcabouço que temos atualmente atende ou se são necessárias mudanças. Por isso, faz-se necessário entender o panorama atual, classificar as empresas e correlacionar com o arcabouço legal da inovação no Brasil, foco deste artigo. Neste sentido, percebe-se que o grande desafio para o Direito é buscar o equilíbrio e acompanhar a velocidade da inovação.

Além do Direito ser estrutura para que a inovação aconteça, também é por ela impactado em sua forma de prestação de serviços. Ou seja, precisa fornecer subsídios ao passo que também se reinventa. Este artigo traz a análise do repertório legislativo nacional sobre inovação e, a partir deste macroentendimento, apresenta a configuração da inovação tecnológica como transformadora do Direito em si.

Em primeira análise, é preciso conceituar inovação. Para o Marco Legal da Inovação, de acordo com o art. 20 da Lei n.o 13.243/16, que alterou o inc. IV do art. 20 da Lei n.o 10.973/04, a definição mais moderna é de que se trata de: 
ISSN 1981-3694

(DOI): $10.5902 / 1981369441419$

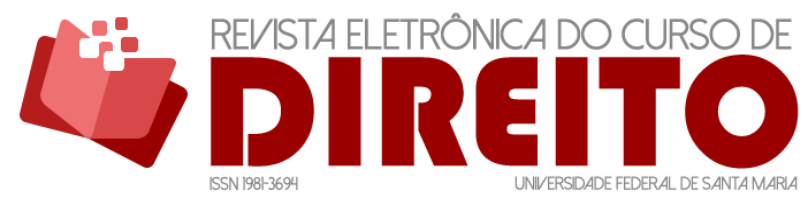

INOVAÇÃO E SUA PRINCIPAL BARREIRA JURÍDICA

Felipe Chiarello De Souza Pinto LARA ROCHA GARCIA

[...] ]introdução de novidade ou aperfeiçoamento no ambiente produtivo e social que resulte em novos produtos, serviços ou processos ou que compreenda a agregação de novas funcionalidades ou características a produto, serviço ou processo já existente que possa resultar em melhorias e em efetivo ganho de qualidade ou desempenho.

Para a doutrina internacional ${ }^{1}$ sobre o tema:

Inovação pode ser definida em diferentes níveis e a partir de diferentes perspectivas dentro desta dinâmica complexa. [...] A complexa dinâmica composta por subsistemas igualmente complexos como forças de mercado, poder político, controle institucional, movimento social, regimes e trajetórias tecnológicas. [...] Inovação, em particular, pode ser definida somente em termos de operação. Tanto o(s) inovador(es) quanto o(s) sistema(s) inovado(s) são transformados pela inovação.

Como se percebe, o elemento constante nas definições, seja ela jurídico-interna ou doutrinária-internacional, é a dinamicidade, complexidade e resultado provocado por uma inovação. São estes, portanto, os principais desafios para a construção normativa de apoio à inovação: acompanhar tais mudanças com a mesma celeridade a qual se aplica também à prática jurídica em si, que passa por uma fase de transformação impactada pela tecnologia.

Para isso, primeiro discutiremos a importância da inovação no cenário econômico nacional, assim como os diplomas jurídicos existentes sobre este tema. Na sequência, passaremos a discutir os atores necessários para se estruturar um ecossistema, sendo os que realizam, os que financiam, os que influenciam e os gerenciam a inovação. Por fim, aplicar à prática jurídica em si, como forma de entender os impactos trazidos pela inovação.

\section{POR QUE FAZER INOVAÇÃO?}

Para Bercovici, o desenvolvimento nacional e o crescimento econômico estão intrinsecamente ligados ao fortalecimento de um sistema de produção econômica, de cunho tecnológico e de inovação ${ }^{2}$. 0 fomento à inovação como alavanca para o desenvolvimento

\footnotetext{
1 Original: "Innovation can be defined at different levels and from different perspectives within this complex dynamics. [...] The complex dynamics of sub dynamics like market forces, political power, institutional control, social movements, technological trajectories and regimes. [...] Innovation, in particular, can be defined only in terms of an operation. Both the innovator(s) and the innovated system(s) are expected to be changed by the innovation."

ETZKOWITZ, Henry e LOET, Leydesdorff. The Dynamics of innovation: from National Systems and 'Mode 2' to a Triple Helix of university-industry-government relations. Reserach Policy 29, pgs 109-123, 2000. Disponível em: http://www.oni.uerj.br/media/downloads/1-s2.0-S0048733399000554-main.pdf. Acesso em: 11 jul. 2020.

2 BERCOVICI, Gilberto et al. O Ordenamento da Inovação Tecnológica em Ação: Lei 10.973/04, Lei 11.196/05 e Lei 11.487/07 - Pesquisa Empírica sobre seus Efeitos. São Paulo: Universidade de São Paulo, 2011.
} 
ISSN 1981-3694

(DOI): $10.5902 / 1981369441419$

econômico nacional é o foco também da Organização das Nações Unidas, nos "17 Objetivos do Desenvolvimento Sustentável”, que dedica o objetivo de número 9 à Inovação e Infraestrutura:

9.a Fortalecer a pesquisa cientifica, melhorar as capacidades tecnológicas de setores industriais em todos os países, particularmente os países em desenvolvimento, inclusive, até 2030, incentivando a inovação e aumentando substancialmente o número de trabalhadores de pesquisa e desenvolvimento por milhão de pessoas e os gastos publico e privado em pesquisa e desenvolvimento.

9.b Apoiar o desenvolvimento tecnológico, a pesquisa e a inovação nacionais nos países em desenvolvimento, inclusive garantindo um ambiente político propício para, entre outras coisas, a diversificação industrial e a agregação de valor às commodities.

9.c Aumentar significativamente o acesso às tecnologias de informação e comunicação e se empenhar para oferecer acesso universal e a preços acessíveis à internet nos países menos desenvolvidos, até $2020^{3}$.

Capacitar as pessoas produzindo capital intelectual é o mote da meta 9.a apresentada. A segunda meta, dirigida aos países em desenvolvimento, entende que a inovação pode ser um caminho para diferenciação agregando valor aos produtos padronizados. A terceira meta, dedicada a Internet e às tecnologias de informação e comunicação, que são as principais utilizadas na prestação jurídica de serviços.

No Brasil, o conjunto legislativo que embasa o Sistema Nacional de Ciência, Tecnologia e Inovação (SNCTI) consiste principalmente, mas não somente, das Leis Federais n.os 13.243/16, 12.349/10, 10.973/04, 11.196/05, $9279 / 96$ e 8.248/91, incluindo também a diretriz constitucional, especialmente pelos artigos 218, 219 e a Emenda Constitucional n. ${ }^{\circ} 85$.

Embora não sejam as únicas leis, este conjunto possibilita entender a estrutura da estratégia da inovação sob o prisma jurídico e seu conceito legal, vinculado aos dispositivos constitucionais. Serão estas as leis a serem analisadas neste artigo em razão da sua relevância nacional e impacto em outras leis. A título didático, construímos a figura 1 dos principais diplomas brasileiros essenciais ao entendimento da inovação em nosso país em cronologia reversa:

3 ORGANIZACÃ̃O DAS NAC,ÕES UNIDAS. Objetivos do Desenvolvimento Sustentável. Disponível em: https://nacoesunidas.org/pos2015/ods9/. Acesso em: 15 nov.2016. 
Figura 1: Principais diplomas brasileiros em Direito da Inovação

\begin{tabular}{|c|c|c|}
\hline ANO & $\begin{array}{l}\text { LEGISLACAO } \\
\text { PRINCIPAL }\end{array}$ & LEGISLACCAO CORRELATA \\
\hline 2018 & $\begin{array}{l}\text { Lei de Proteção de } \\
\text { Dados Pessoais (Lei } \\
\text { 13.709) }\end{array}$ & Lei 12.965 - Marco Civil da Internet \\
\hline 2016 & $\begin{array}{l}\text { Marco Legal da } \\
\text { Inovação (Lei 13.243) }\end{array}$ & $\begin{array}{l}\text { Lei } 10.973 / 04 \text { - Lei de Inovação Tecnológica } \\
\text { Lei } 6.815 / 80 \text { - Estatuto do estrangeiro } \\
\text { Lei } 8.666 / 93 \text { - Lei de licitações } \\
\text { Lei } 12.462 / 11 \text { - Regime diferenciado de contrataçães } \\
\text { Lei } 8.745 / 93 \text { - Contratação temporária em autarquias, fundações e administração direta Lei } \\
8958 / 94 \text { - Sobre ICT } \\
\text { Lei } 8010 / 90 \text { - Sobre bens destinados à pesquisa científica e tecnológica Lei } 8032 / 99 \text { - Sobre imposto } \\
\text { de importação } \\
\text { Lei } 12.772 / 12 \text { - Sobre carreiras do magistério público }\end{array}$ \\
\hline 2015 & $\begin{array}{l}\text { Emenda } \\
\text { Constitucional } 85\end{array}$ & Não se aplica \\
\hline 2014 & $\begin{array}{l}\text { Marco Civil da } \\
\text { Internet (Lei 12.965) }\end{array}$ & Não se aplica \\
\hline 2010 & $\begin{array}{l}\text { Lei do Poder de } \\
\text { Compra Nacional (Lei } \\
\text { 12.349) }\end{array}$ & $\begin{array}{l}\text { Lei } 8.666 / 93 \text { - Lei de licitações } \\
\text { Lei } 8.958 / 94 \text { - Sobre instituições federais de ensino superior e fundações Lei } 10.973 / 04 \text { - primeira } \\
\text { lei de inovação } \\
\text { Lei } 11.273 / 66 \text { - Sobre bolsas de estudo }\end{array}$ \\
\hline 2005 & $\begin{array}{l}\text { Lei do Bem (Lei } \\
11.196)\end{array}$ & 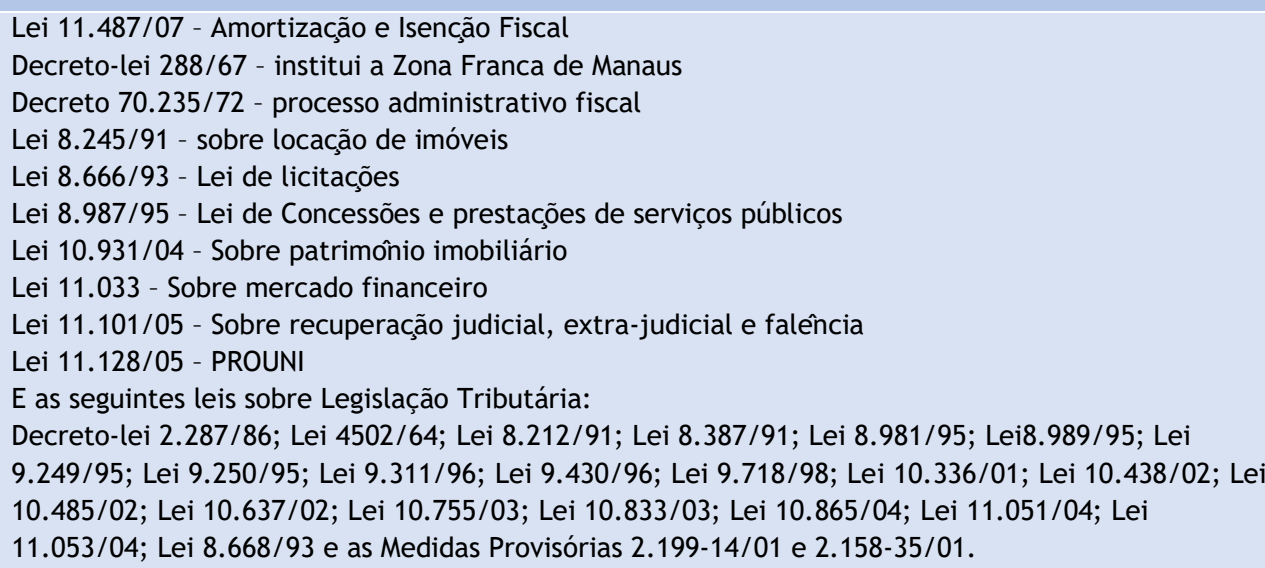 \\
\hline 2004 & $\begin{array}{l}\text { Primeira Lei de } \\
\text { Inovação (Lei 10.973) }\end{array}$ & Não se aplica \\
\hline 1996 & $\begin{array}{l}\text { Lei de Patentes (Lei } \\
\text { 9.279) }\end{array}$ & Estatuto e Procedimentos do Instituto Nacional de Propriedade Intelectual (INPI) \\
\hline 1991 & $\begin{array}{l}\text { Lei de Informática } \\
\text { (Lei 8.248) }\end{array}$ & Não se aplica \\
\hline 1988 & $\begin{array}{l}\text { Constituição Federal - } \\
\text { artigos } 218 \text { e } 219\end{array}$ & Não se aplica \\
\hline
\end{tabular}

Em 2015 foi promulgada a Emenda Constitucional n. ${ }^{\circ}$ 85, com o intuito de alterar oito dispositivos constitucionais para incluir a palavra "inovação", com o intuito de dar ainda mais destaque e importância ao conceito no diploma. Esta emenda procura fomentar a inovação em 
ISSN 1981-3694

(DOI): $10.5902 / 1981369441419$

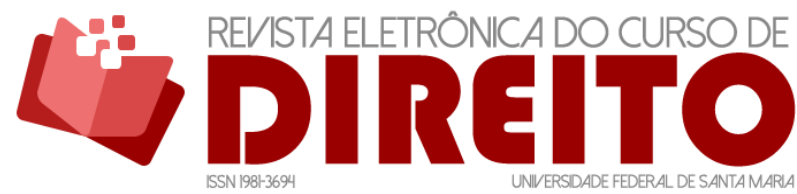

INOVAÇÃO E SUA PRINCIPAL BARREIRA JURÍDICA

Felipe Chiarello De SOUZa Pinto LARA ROCHA GARCIA

território nacional, priorizando a produção de novos produtos, serviços ou processos, e não a sua mera adoção, sejam eles de base tecnológica ou não.

Em perspectiva histórica, a Constituição buscou estabelecer bases jurídicas para isso, sendo essa expressão, inclusive, um dos objetivos previstos nominalmente no inciso II, e, indiretamente, no inciso IV do seu artigo 3o. Comentando os arts. 218 e 219, Braga afirma que a Constituição:

[...] deu grande relevância ao papel da ciência e da tecnologia no desenvolvimento econômico, fato que de acordo com Grau (2008, p.265), está relacionado à função que o conhecimento desempenha na sociedade atualmente. Como é sabido, o nível de desenvolvimento socioeconômico de um país jáa não é mais medido pela acumulação de capital, mas também de saberes científicos e conhecimento técnico ${ }^{4}$.

Estes artigos, que são dedicados aos temas de ciência, tecnologia e inovação, exprimem verbos positivos e diretivos, como "promoverá”, “incentivará”, “apoiará” e “estimulará”. Em outras palavras, cabe ao Estado, na direção prevista constitucionalmente, editar legislação coerente e promover políticas públicas de incentivo às inovações tecnológicas, que podem ser um caminho para o desenvolvimento tecnológico e científico. Este, por sua vez, influenciaria o próprio desenvolvimento nacional. A EC 85 foi protagonista do Marco Legal da Inovação.

Em matéria infraconstitucional, a lei mais especifica sobre o tema recebeu a alcunha de Marco Legal da Inovação (Lei Federal n.o 13.243/16). Tal marco tem o intuito de diminuir as barreiras para a promoção da inovação, ampliar a possibilidade de colaboração entre academia e iniciativa privada, ampliar a participação dos pesquisadores e professores em papéis mais estratégicos e com maior tempo de dedicação, disponibilizar capital intelectual em projetos colaborativos e sedimentar alguns conceitos acerca dos atores da inovação. Sobre ela pendem várias críticas, especialmente por parte da iniciativa privada, pois a lei foi promulgada com oito vetos ao projeto original, especialmente nos itens que se referem a isenção fiscal.

Antes dela, em 2014, foi promulgado o Marco Civil da Internet, que simboliza o reconhecimento desta rede como instrumento inerente à sociedade humana. Assim, se faz necessário buscar segurança jurídica para todos os produtos e serviços que emanam da rede, são criados por ela ou mesmo se desenvolvem somente pela rede. Não teve, no entanto, o intuito de engessar ou proibir, mas discutir neutralidade, sujeitos de direito e princípios gerais.

${ }^{4}$ BRAGA, Marco Aurélio Cezarino. Artigos 218 e 219: técnica constitucional para superação do subdesenvolvimento. São Paulo: [s.n], [2007-]. 
ISSN 1981-3694

(DOI): $10.5902 / 1981369441419$

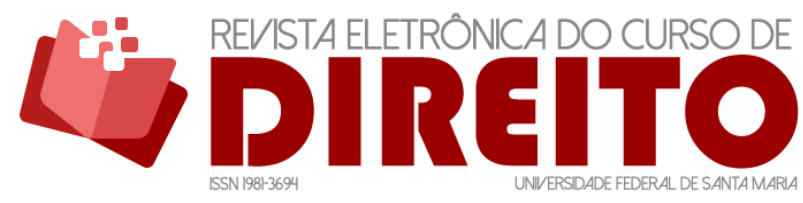

INOVAÇÃO E SUA PRINCIPAL BARREIRA JURÍDICA

Nas palavras de Abrusio, Del Masso e Florêncio Filho:

o propósito da rede social tem sido reconhecido. Novos serviços e canais de relacionamento emergem todo o tempo, e a lei deve, pelo menos, tentar estabelecer princípios gerais e garantias inequívocas para um melhor relacionamento com a internet. É nesse sentido que a lei pode ajudar. ${ }^{5}$

Essa lei dialoga com a mais recente, a Lei de Proteção de Dados Pessoais, especialmente porque também discute questões de privacidade. Sobre isso, os mesmos autores defendem que a rede deve continuar com a sua natureza participativa, assim como com liberdade para criar modelos de negócio.

A proteção da privacidade e dados pessoais, a preservação da neutralidade da rede e sua natureza participativa, assim como a liberdade de modelos de negócios promovidos na internet, tem sido tratados como princípios primeiros em outras palavras, nem todas as repercussões jurídicas têm sido tratadas com a lei. O escopo prático de algumas regulações ainda não é sabido, portanto, a contribuição da doutrina legal e o surgimento dos primeiros julgados envolvendo estes assuntos irão contribuir de forma decisiva na construção de uma disciplina legal para a internet no Brasil. ${ }^{\circ}$

Considerando a relevância da questão da privacidade e dos dados pessoais, em 2018, a Lei de Proteção de Dados Pessoais, seguindo o exemplo da GDPR Europeia (General Data Protection Regulation) define o que são dados pessoais assim como seus titulares logo no artigo 5. Também neste artigo traz outras definições importantes, como quem e o que pode ser feito com os dados a serem tratados. Para isso, de forma específica, determina 10 bases legais, previstas no artigo $7 .{ }^{7}$

\footnotetext{
${ }^{5}$ Original: "the network's social purpose has been recognized. New services and relationship channels arise all the time, and the law must at least try to establish general principles and unequivocal guarantees for a better relationship with the internet. It's in this sense that the new law can help". DEL MASSO, Fabiano; ABRUSIO, Juliana; FLORENCIO FILHO, Marco Aurélio. The Legal Rights Framework for the Internet in Brazil. Disponível em: http://www.legalcurrent.com/the-civil-rights-framework-forthe-internet-in-brazil/. Acesso em: 22 de nov. 2017.

${ }^{6}$ Original: "The protection of privacy and personal data, the preservation of the network 's neutrality and its participatory nature, as well as the freedom of the business models promoted on the internet, have been treated as first principles - in other words, not all the juridical repercussions have been dealt with in the law. The practical scope of these regulations is still not know, so that the contribution of legal doctrine and the handing down of the first judgments involving theses subjects will also contribute in a decisive way to the building of a legal discipline for the internet in Brazil".

DEL MASSO, Fabiano; ABRUSIO, Juliana; FLORENCIO FILHO, Marco Aurélio. The Legal Rights Framework for the Internet in Brazil. Disponível em: http://www.legalcurrent.com/the-civil-rights-framework-forthe-internet-in-brazil/. Acesso em: 22 de nov. 2017.

${ }^{7}$ Art. 700 tratamento de dados pessoais somente poderá ser realizado nas seguintes hipóteses:

I - mediante o fornecimento de consentimento pelo titular; II - para o cumprimento de obrigação legal ou regulatória pelo controlador; III - pela administração pública, para o tratamento e uso compartilhado de dados necessários à execução de políticas públicas previstas em leis e regulamentos ou respaldadas em contratos, convênios ou instrumentos congêneres, observadas as disposições do Capítulo IV desta Lei; IV - para a realização de estudos por órgão de pesquisa, garantida, sempre que possível, a anonimização
} 
ISSN 1981-3694

(DOI): $10.5902 / 1981369441419$

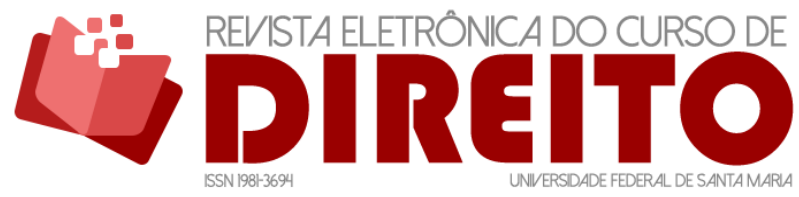

INOVAÇÃO E SUA PRINCIPAL BARREIRA JURÍDICA

A Lei de Proteção de Dados Pessoais pretende regular a classificação do dado, sua captação, tratamento, utilização e comercialização, reconhecendo-o como um ativo economicamente relevante. Seria o equivalente ao realizado pela lei europeia, GDPR. A revista The Economist ${ }^{8}$, em uma de suas matérias de capa, afirma que "o recurso mais valioso não é mais petróleo, mas dados"'. Isso porque visualiza que as empresas que mais lidam com dados comercialmente - Amazon, Apple, Facebook, Google e Microsoft, por exemplo, se beneficiam cada vez mais dos dados que colhem ao proverem um serviço.

0 valor do dado reside em perceber que, a partir do entendimento mais profundo do cliente, seus interesses e comportamentos, é possível criar produtos e serviços melhores, o que fará com eles usem cada vez mais tais produtos e serviços. Aumentando o uso, cresce também a quantidade de dados adquiridos e informações sobre os clientes. Cria-se, assim, um ciclo, que pode ser virtuoso ou vicioso, inclusive sob o ponto de vista econômico.

Ao se coletar mais dado, uma empresa tem mais informação para melhorar seus produtos, o que atrai mais usuários, gerando ainda mais dados, e assim por diante. [...]

Mais transparência ajudaria: empresas seriam forçadas a revelar aos consumidores quais informações eles guardam e quanto monetizam a partir delas. Governos poderiam encorajar o surgimento de novos serviços ao abrir seus próprios dados ou gerenciar partes cruciais da economia dos dados como infraestrutura pública. [...]

Mas se os governos não querem uma economia de dados dominadas por alguns gigantes, eles precisam agir rápido.

${ }_{10}$.

dos

dados

pessoais;

V - quando necessário para a execução de contrato ou de procedimentos preliminares relacionados a contrato do qual seja parte o titular, a pedido do titular dos dados; VI - para o exercício regular de direitos em processo judicial, administrativo ou arbitral, esse último nos termos da Lei no 9.307, de 23 de setembro de 1996 (Lei de Arbitragem); VII - para a proteção da vida ou da incolumidade física do titular ou de terceiro; VIII - para a tutela da saúde, em procedimento realizado por profissionais da área da saúde ou por entidades sanitárias;

IX - quando necessário para atender aos interesses legítimos do controlador ou de terceiro, exceto no caso de prevalecerem direitos e liberdades fundamentais do titular que exijam a proteção dos dados pessoais; ou

X - para a proteção do crédito, inclusive quanto ao disposto na legislação pertinente.

${ }^{8}$ Original: "the world's most valuable resource is no longer oil, but data."

THE ECONOMIST. Regulating the internet giants: The world's most valuable resource is no longer oil, but data. Disponível em: https://www.economist.com/leaders/2017/05/06/the-worlds-most-valuableresource-is-no-longer-oil-but-data. Acesso em: 20 dez. 2017.

9 ibidem.

${ }^{10}$ Original: "by collecting more data, a firm has more scope to improve its products, which attracts more users, generating even more data, and so on.

[...]

More transparency would help: companies could be forced to reveal to consumers what information they hold and how much money they make from it. Governments could encourage the emergence of new 
ISSN 1981-3694

(DOI): $10.5902 / 1981369441419$

O que a Lei de Proteção de Dados Pessoais busca, como um dos 10 princípios trazidos pelo artigo 6, é a mesma transparência citada pela The Economist, por meio "de garantia, aos titulares, de informações claras, precisas e facilmente acessíveis sobre a realização do tratamento e os respectivos agentes de tratamento, observados os segredos comercial e industrial" $"$.

Em continuidade ao quadro sintético, a Lei Federal n.o 12.349, de 15 de dezembro de 2010, conhecida como Lei do Poder de Compra Nacional, tem como principal intuito flexibilizar as regras previstas na lei de licitação no caso de projetos de inovação, com vistas à facilitação e ao estímulo da parceria público-privada na atividade.

Por fim, a Lei Federal n.o 11.196, de 21 de novembro de 2005, conhecida como Lei do Bem, dispõe, essencialmente, sobre incentivos fiscais para a inovação tecnológica e regimes especiais de exportação de serviços de tecnologia da informação, aquisição de bens de capital e inclusão digital.

A Lei Federal n.o 9.279, de 14 de maio de 1996, que regula direitos e obrigações relativos à propriedade industrial, é o principal diploma legal do sistema patentário nacional sob a gestão do Instituto Nacional da Propriedade Industrial (INPI). Este instituto é o único responsável por fazer toda a gestão dos pedidos e concessão. Para isso, possui estatuto, processos e procedimentos próprios.

A Lei Federal n.o 8.248, de 23 de outubro de 1991, conhecida como Lei de Informática, dispõe sobre a capacitação e competitividade do setor de informática e automação, tem objetivo de incentivar que empresas de tecnologia invistam em inovação e pesquisa cientifica. Para isso, exige uma certificação por meio de uma Comissão do Ministério de Ciência, Tecnologia e Inovação chamada de CATI - Comitê da Área de Tecnologia de Informação. Os institutos de ciência e tecnologia que forem certificados por este comitê podem realizar projetos de inovação

services by opening up more of their own data vaults or managing crucial parts of the data economy as public infrastructure.

[...]

But if governments don't want a data economy dominated by a few giants, they will need to act soon"

THE ECONOMIST. Regulating the internet giants: The world's most valuable resource is no longer oil, but data. Disponível em: https://www.economist.com/leaders/2017/05/06/the-worlds-most-valuableresource-is-no-longer-oil-but-data. Acesso em: $20 \mathrm{dez} .2017$.

${ }^{11}$ BRASIL. LEI $\mathrm{n}^{\circ} 13.709, \quad$ de 14 de agosto de 2018. Lei Geral de Proteção de Dados Pessoais (LGPD). Diário Oficial da República Federativa do Brasil, Brasília, DF, 14 ago. 2018. Disponível em: http://www.planalto.gov.br/ccivil_03/_Ato20152018/2018/Lei/L13709.htm. Acesso em: 11 jul. 2020. 
ISSN 1981-3694

(DOI): $10.5902 / 1981369441419$

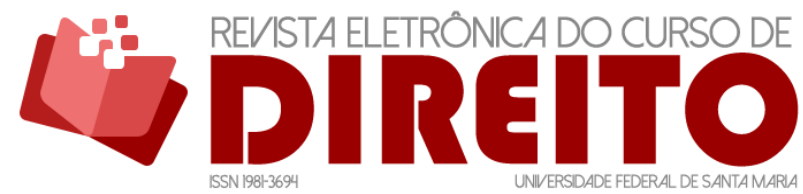

INOVAÇÃO E SUA PRINCIPAL BARREIRA JURÍDICA

Felipe Chiarello De SOUZa Pinto LARA ROCHA GARCIA

financiados por empresas de informática e automação que, por sua vez, receberão incentivos fiscais previstos na Lei de Informática.

A Lei Federal n.o 10.973, de 2 de dezembro de 2004, dispõe sobre incentivos à inovação e à pesquisa científica e tecnológica. Considerada um dos primeiros marcos jurídicos sobre o tema, ela define as diretrizes de relacionamento entre agência de fomento, pesquisadores e inventores, a criação em si e sua correlação com o sistema patentário nacional, instituições cientificas e tecnológicas (ICT), núcleos de inovação tecnológica (NIT) e fundação de instituições de apoio. Lançada para estimular a produção e a inovação como elemento de desenvolvimento econômico nacional, ela prevễ a integração entre investimento público, academia e iniciativa privada com alguns entraves que a Lei n.o 13.243 pretendeu reduzir em 2016.

Em âmbito estadual, também encontramos alguns estados que editaram legislação específica $^{12}$ com o intuito de promover a inovação. Cada uma delas traz em seu bojo incentivos fiscais de competência estadual, ou, ainda, discricionariedades administrativas de flexibilização, especialmente em relação a fomento e relacionamento com a academia.

Barreto Junior e Cesar, em seu artigo sobre o marco civil da internet, discute sobre as respostas legais para os desafios que a tecnologia e inovação, por meio da internet, no entanto, reconhecem que "o Direito possui uma velocidade muito mais lenta que as evoluções tecnológicas, então esse mundo digital possui muito a ser juridicamente discutido e trabalhado"13.

\section{QUEM FAZ A INOVAÇÃO?}

Além dos diplomas existentes que oferecem base para a Inovação, é preciso entender também os atores e sujeitos de direito que compõe o sistema jurídico.

\footnotetext{
12 Alagoas - Lei n.o 7.117/09; Amazonas - Lei n.o 3.095/06; Bahia - Lei n.o 11.174/08; Ceará - Lei n.o 14.220/08; Goiás - Lei n.o 16.922/10; Mato Grosso - Lei Complementar n.o 297/08; Minas Gerais - Lei n.o 17.348/08; Pernambuco - Lei n.o 13.690/08; Rio de Janeiro - Lei n.o 5.361/08; Rio Grande do Sul - Lei n.o 13.196/09; Santa Catarina - Lei n.o 14.328/08; São Paulo - Lei Complementar n.o 1.049/08 e Sergipe - Lei n.o 6.794/09.

13 CÉSAR, Daniel; BARRETO JUNIOR, Irineu Francisco. Marco civil da internet e neutralidade da rede: aspectos jurídicos e tecnológicos. Revista Eletrônica do Curso de Direito da UFSM, Santa Maria, RS, v. 12, n. 1, p. 65-88, abr. 2017. ISSN 1981-3694. DOI: http://dx.doi.org/10.5902/1981369423288. Disponível em: https://periodicos.ufsm.br/revistadireito/article/view/23288. Acesso em: 20 jul. 2017.
} 
A doutrina internacional apresenta o modelo tríplice hélice, que entende que as relações entre o Estado, a Academia e a Iniciativa Privada devem se fortalecer e encontrar agenda em comum entre todos eles, ou entre alguns deles, como na figura 2 abaixo: ${ }^{14}$

Figura 2: Modelo de Tríplice Hélice da Inovação

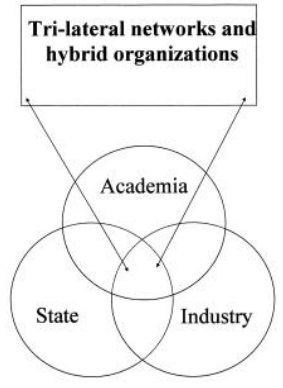

Do ponto de vista legal, o Marco Legal da Inovação buscou apresentar e conceituar os principais atores que incidem sobre o processo de inovação ao alterar a redação dos incisos do artigo 20 da Lei n.o 10.973/04 ${ }^{15}$. Também a LGPD, como vimos, traz em seu bojo definição que

${ }^{14}$ ETZKOWITZ, Henry e LOET, Leydesdorff. The Dynamics of innovation: from National Systems and 'Mode 2'to a Triple Helix of university-industry-government relations. Reserach Policy 29, pgs 109-123, 2000. Disponível em: http://www.oni.uerj.br/media/downloads/1-s2.0-\$0048733399000554-main.pdf. Acesso em: 07 jul. 2020.

15 Art. o. [...] III - criador: pessoa física que seja inventora, obtentora ou autora de criação; III-A - incubadora de empresas: organização ou estrutura que objetiva estimular ou prestar apoio logístico, gerencial e tecnológico ao empreendedorismo inovador e intensivo em conhecimento, com o objetivo de facilitar a criação e o desenvolvimento de empresas que tenham como diferencial a realização de atividades voltadas à inovação; V - Instituição Científica, Tecnológica e de Inovação (ICT): órgão ou entidade da administração pública direta ou indireta ou pessoa jurídica de direito privado sem fins lucrativos legalmente constituída sob as leis brasileiras, com sede e foro no País, que inclua em sua missão institucional ou em seu objetivo social ou estatutário a pesquisa básica ou aplicada de caráter científico ou tecnológico ou o desenvolvimento de novos produtos, serviços ou processos; VI - Núcleo de Inovação Tecnológica (NIT): estrutura instituída por uma ou mais ICTs, com ou sem personalidade jurídica própria, que tenha por finalidade a gestão de política institucional de inovação e por competências mínimas as atribuições previstas nesta Lei; VII - fundação de apoio: fundação criada com a finalidade de dar apoio a projetos de pesquisa, ensino e extensão, projetos de desenvolvimento institucional, científico, tecnológico e projetos de estímulo à inovação de interesse das ICTs, registrada e credenciada no Ministério da Educação e no Ministério da Ciência, Tecnologia e Inovação, nos termos da Lei no 8.958, de 20 de dezembro de 1994, e das demais legislações pertinentes nas esferas estadual, distrital e municipal; VIII - pesquisador público: ocupante de cargo público efetivo, civil ou militar, ou detentor de função ou emprego público que realize, como atribuição funcional, atividade de pesquisa, desenvolvimento e inovação;

$\mathrm{X}$ - parque tecnológico: complexo planejado de desenvolvimento empresarial e tecnológico, promotor da cultura de inovação, da competitividade industrial, da capacitação empresarial e da promoção de sinergias em atividades de pesquisa científica, de desenvolvimento tecnológico e de inovação, entre 
ISSN 1981-3694

(DOI): $10.5902 / 1981369441419$

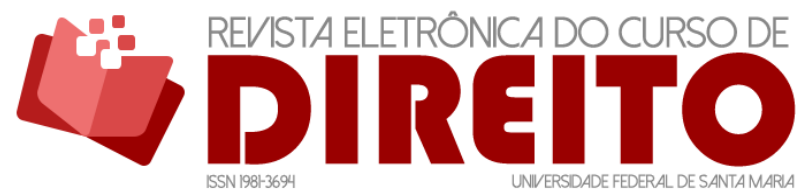

INOVAÇÃO E SUA PRINCIPAL BARREIRA JURÍDICA

Felipe Chiarello De Souza Pinto LARA ROCHA GARCIA

diferencia o controlador do operador de dados. Ambos têm deveres especificados pela lei, que também traz como novidade a necessidade de criação de um novo cargo nas empresas que, pela letra da lei, recebe o nome de encarregado de dados, mas, nas empresas, encontra-se mais comumente DPO - Data Protection Officer.

Além destes papéis, controlador, operador e DPO, a LGPD acrescenta um órgão da administração pública de relevância fundamental. A Autoridade Nacional de Proteção de Dados (ANPD) tem a obrigação de zelar, implementar e fiscalizar o cumprimento da lei, e a ela é atribuída a máxima importância de aplicar qualquer das sanções previstas no artigo 52, isoladas com combinadas.

Em 2014, a Associação Nacional de Pesquisa e Desenvolvimento das Empresas Inovadoras (ANPEI) mapeou os atores da inovação no país e suas possibilidades de interação, assim como a intensidade delas, como se vê na figura $3^{16}$.

Também ela entende, como no modelo proposto pela doutrina, que a inovação acontece pela união da academia, com as universidades públicas e particulares, especialmente de ensino superior; com o incentivo estatal, através de políticas públicas, poder de compra e, principalmente, isenções fiscais; assim como com o capital da iniciativa privada e sua capacidade de movimentar a economia e escalar a produção.

De um lado, a sociedade demanda por novos produtos ou serviços, que pode ser tratada pelos Institutos de Ciência e Tecnologia (ICT) públicos, privados ou ainda que pertençam a uma universidade. Ou essa mesma demanda pode ser endereçada por empresas situadas nos parques tecnológicos, incubadoras ou núcleos de inovação tecnológica. Por vezes, até mesmo as empresas, por meio de seus departamentos de inovação ou pesquisa e desenvolvimento, podem endereçar soluções. Os investidores, por sua vez, têm papel no desenvolvimento econômico dos produtos/serviços.

A figura 3 apresenta a relevância estatal. Ainda que não seja o responsável por resolver as demandas, cabe ao Estado prover formas de fomento, educação, infraestrutura e regulação, tema deste artigo.

empresas e uma ou mais ICTs, com ou sem vínculo entre si;
$\mathrm{XI}$ - polo tecnológico: ambiente industrial e tecnológico caracterizado pela presença dominante de micro, pequenas e médias empresas com áreas correlatas de atuação em determinado espaço geográfico, com vínculos operacionais com ICT, recursos humanos, laboratórios e equipamentos organizados e com predisposição ao intercâmbio entre os entes envolvidos para consolidação, marketing e comercialização de novas tecnologias";

${ }^{16}$ ASSOCIACÃO NACIONAL DE PESQUISA E DESENVOLVIMENTO DAS EMPRESAS INOVADORAS. Mapa do sistema brasileiro de inovação. In: 14a CONFERENCIA ANPEI DE INOVAÇ̃̃O TECNOLÓGICA, São Paulo, 28 abr. 2014. Disponível em: http://anpei.org.br/download/Mapa_SBI_Comite_ANPEI_2014_v2.pdf. Acesso em: 11 jul. 2020. 
Figura 3: Mapa de atores da Inovação ${ }^{17}$

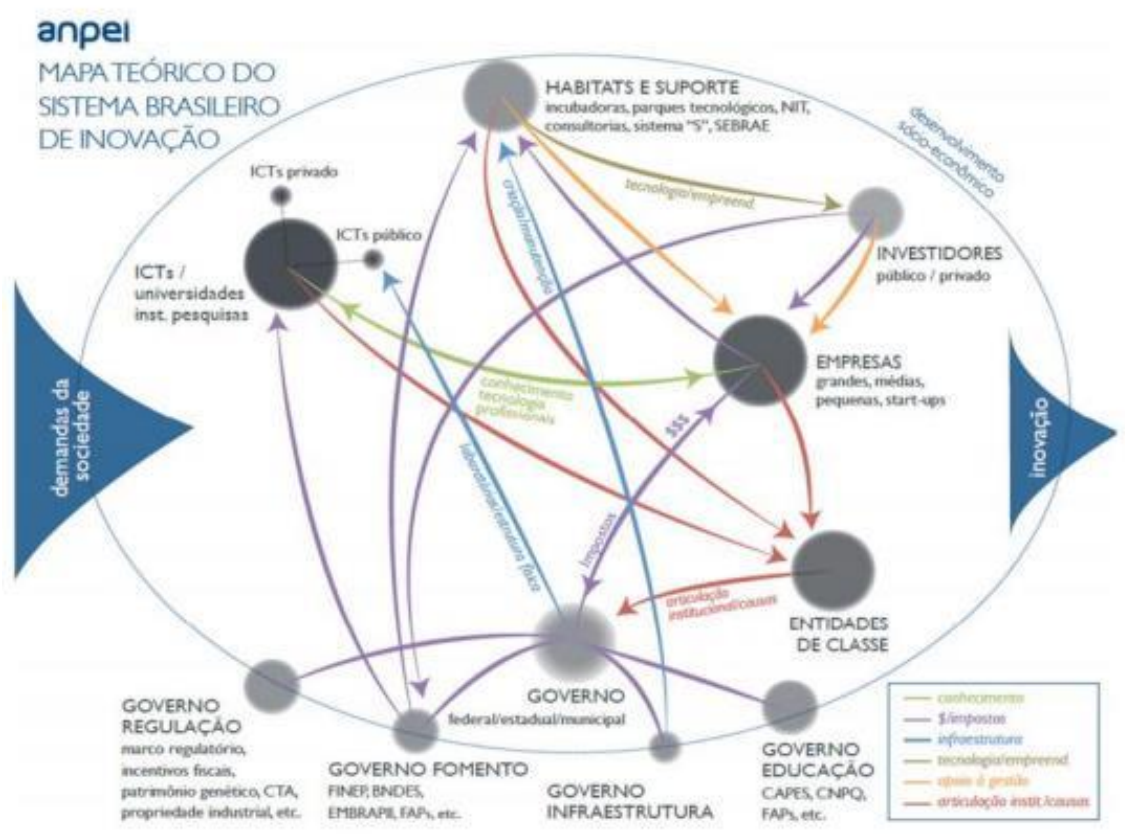

O mapeamento da figura 3 oferece uma leitura interessante, com um panorama dos atores envolvidos. No entanto, não é o único tipo de mapeamento de atores da inovação que encontramos. Bercovici, no relatório de pesquisa "O Ordenamento da Inovação Tecnológica em Ação", dividem os atores descritos na legislação de acordo com a ação que podem ter no sistema de inovação: aqueles que financiam a inovação; que realizam e gerenciam a inovação; e que sugerem a política de inovação ${ }^{18}$.

De acordo com os autores, os que financiam podem ser em âmbito público, como o Banco Nacional de Desenvolvimento Social (BNDES), Financiadora de Estudos e Projetos (FINEP), Conselho Nacional de Desenvolvimento Científico e Tecnológico (CNPq), Fundações Estaduais de Amparo à Pesquisa, Agências de Fomento, Aceleradoras e Incubadoras públicas - ou em âmbito privado - Fundos de Investimento Venture Capital ou Private Equity, Empresas Privadas com seus departamentos de inovação, Aceleradora e Incubadoras privadas.

17 ASSOCIACÃO NACIONAL DE PESQUISA E DESENVOLVIMENTO DAS EMPRESAS INOVADORAS. Mapa do sistema brasileiro de inovação. In: 14a CONFERENCIA ANPEI DE INOVAÇ̃̃O TECNOLÓGICA, São Paulo, 28 abr. 2014. Disponível em: http://anpei.org.br/download/Mapa_SBI_Comite_ANPEI_2014_v2.pdf. Acesso em: 11 jul. 2020.

18 BERCOVICl, Gilberto et al. O Ordenamento da Inovação Tecnológica em Ação: Lei 10.973/04, Lei 11.196/05 e Lei 11.487/07 - Pesquisa Empírica sobre seus Efeitos. São Paulo: Universidade de São Paulo, 2011. 
ISSN 1981-3694

(DOI): $10.5902 / 1981369441419$

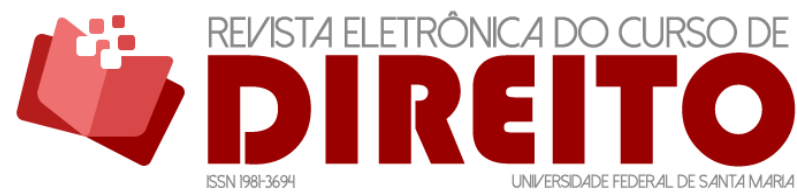

INOVAÇÃO E SUA PRINCIPAL BARREIRA JURÍDICA

Felipe Chiarello De Souza Pinto LARA ROCHA GARCIA

Para Sunstein, um direito é "child of the law"19, ou seja, deriva da lei. Na interpretação de Garcia. Dessa forma, quando este aparato declarar algo como direito, faz- se necessário entender que existirão custos inerentes para suportá-lo, o que será feito seja integralmente pelos cofres públicos, seja dividido com a iniciativa privada. Em última consequência, declarar direitos sem que exista a possibilidade prática de exercê-los, na visão de Sunstein, seria quase o mesmo que negar direitos. ${ }^{20}$

Inovação é uma forma de buscar o desenvolvimento nacional, independente de quem a realiza, sejam entes públicos ou privados. Nessa perspectiva, entender os custos e as possibilidades de financiamento são elementos fundamentais.

Os sujeitos que realizam e gerenciam são os criadores e inventores, os institutos de ciência e tecnologia (ICT) públicos e privados, os núcleos de inovação tecnológica (NIT) públicos e privados, as instituições de apoio públicas e privadas e também as empresas privadas, como as startups. As lawtechs e legaltechs entram nesse contexto como sujeito de realização da inovação com o intuito de, por meio de tecnologia, transformar a prática jurídica.

No entanto, lawtechs/legaltechs são diferentes de ICT e NIT pois são pessoas jurídicas com fins lucrativos e, por isso, devem buscar a melhor sociedade empresária que as representem.

Além destes sujeitos que realizam a inovação, possuem papel relevante no ecossistema de inovação as associações que representam um setor da economia, como, por exemplo, a Associação Brasileira de Desenvolvimento Industrial (ABDI), que tem como papel indicar os problemas existentes que carecem de inovação. Neste sentido, seu papel fundamental ocorre como influenciador da direção do que deve ser objeto da inovação. Bercovici utiliza o verbo "sugerir" para tal ação.

Neste tipo de classificação, é possível encontrar os sujeitos em mais de uma categoria. Por isso, financiamento, execução, gestão e sugestão (ou influência) são funções de todos os atores e sujeitos do Sistema Nacional de Ciência e Inovação. Este entendimento se aproxima do gráfico produzido pela ANPEI, em que os atores não estão ligados linearmente e nem com apenas uma função, mas sim como um conjunto delas de acordo com o papel que o caso concreto demanda.

19 "Filho da lei". SUNSTEIN, Cass; HOLMES, Stephen. The Cost of Rights: Why Liberty Depends on Taxes. New York: W. W. Norton \& CO, 1999, p. 4.

20 GARCIA, Lara Rocha. Inovação Tecnológica e Direito à Saúde: Aspectos Jurídicos, Econômicos, Tecnológicos e de Políticas Públicas. Curitiba: Juruá, 2017, pg. 48. 


\section{INOVAÇÃO NO DIREITO: IMPACTO DAS LEGALTECHS NA TRANSFORMACÃ̃O DA PRÁTICA JURÍDICA}

O cenário atual das legaltechs é ainda fragmentado, seja no Brasil ou mesmo no mundo. Há uma grande dificuldade de defini-las, assim como de categorizá-las em grupos estruturados, ainda que sejam analisadas em termos de tipos de solução, localização geográfica, solução tecnológica ou mesmo usuário final.

O instituto de pesquisas CB Insights, assim como os autores Tobschall, Veith et al, e Wilson, em seus estudos fizeram algumas tentativas.

Veith ${ }^{21}$ sugere 3 tipos de distinção de acordo com:

i. Limites de jurisdição de cada país

ii. Usuário final - dividido em:
a. Advogado para Advogado (L2L);
b. Advogado para Empresa (L2B) e
c. Advogado para cliente (L2C).

iii. Solução tecnológica
a. Tecnologia facilitadora (Enabler)
b. Suporte a decisão (Support Process Solutions)
c. Atividades próprias de profissionais (Substantive Law Solutions)

Figura 4: Legal Technology Framework22

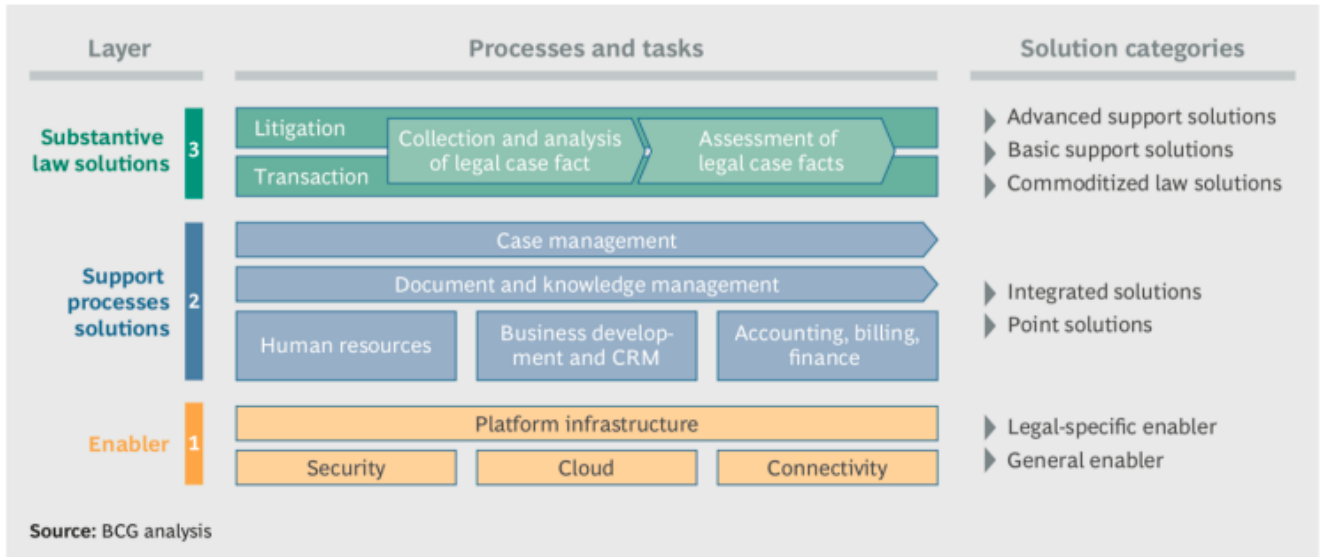

21 VEITH, C.; BANDLOW, M.; HARNISCH, M., WENZLER, H.; HARTUNG, M.; e HARTUNG, D. How Legal Technology Will Change the Business of Law. The Boston Consulting Group \& Bucerius Law School. Disponível em: http://media-publications.bcg.com/How-legal-tech-will-change-business-of-low.pdf. Acesso em: 11 jul. 2020.

22 VEITH, C.; BANDLOW, M.; HARNISCH, M., WENZLER, H.; HARTUNG, M.; e HARTUNG, D. How Legal Technology Will Change the Business of Law. The Boston Consulting Group \& Bucerius Law School. Disponível em: http://media-publications.bcg.com/How-legal-tech-will-change-business-of-low.pdf. Acesso em: 11 jul. 2020. 
ISSN 1981-3694

(DOI): 10.5902/1981369441419

UDIREITO

INOVAÇÃO E SUA PRINCIPAL BARREIRA JURÍDICA

Além dessas três, Andreae ${ }^{23}$ propõe, em sua tese de mestrado, grupos mais específicos, tais como, detalhados na Figura 5:

i. Soluções padronizadas por meio de plataformas de auto-serviços (Commoditized law solution via self-service platforms) ;

ii. Ferramentas de alta tecnologia para tipos específicos de serviços jurídicos (HighTech tools for specific types of legal services) ;

iii. Plataformas eletrônicas de comércio, construção de rede e multifaces (Eletronic legal marketplaces, networks and multisided platforms) ;

iv. $\quad$ Plataforma disruptiva (Disruptive platform) ;

v. Sistema de inteligência artificial (Legal artificial intelligence systems) .

Figura 5: Types of Legaltechs Startups ${ }^{24}$

\section{Types of Legal Tech Startups}
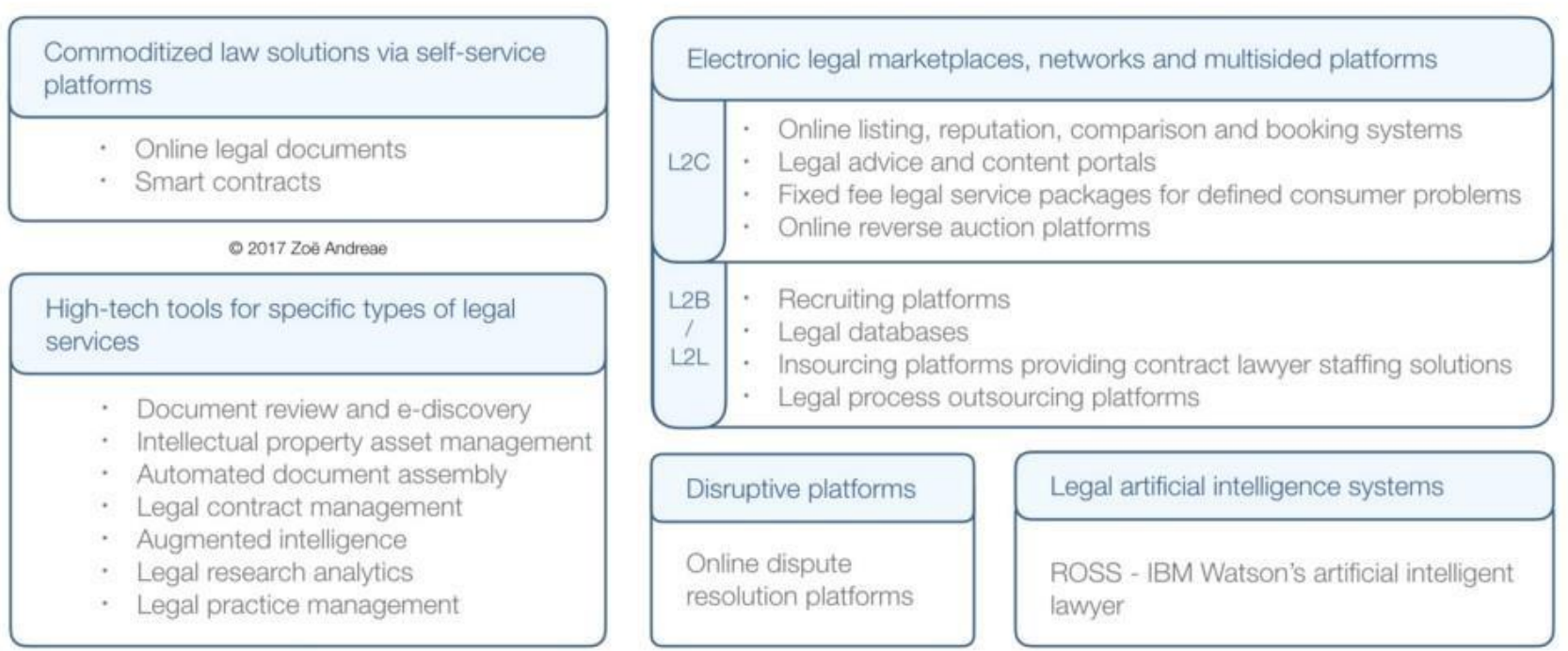

Em qualquer destas classificações, dados de naturezas diversas serão transitados assim como tratados para vários fins. Em pesquisa realizada nos últimos 3 anos pelos institutos The

${ }^{23}$ ANDREAE, Zoë. The Role of Legal Tech Startups in the Digital Transformation of the German Legal Industry. 2016. $78 \mathrm{f}$. Dissertação (Master of Science in Innovation and Entrepreneurship) - Department of Operations, Innovation and Data Sciences, ESADE Business School, Barcelona, 2016. Disponível em: http://dd.lecare.com/legaltech.pdf. Acesso em: 30 dez. 2018.

${ }^{24}$ ANDREAE, Zoe". The Role of Legal Tech Startups in the Digital Transformation of the German Legal Industry. 2016. 78 f. Dissertação (Master of Science in Innovation and Entrepreneurship) - Department of Operations, Innovation and Data Sciences, ESADE Business School, Barcelona, 2016. Disponível em: http://dd.lecare.com/legaltech.pdf. Acesso em: 30 dez. 2018. 
ISSN 1981-3694

(DOI): $10.5902 / 1981369441419$

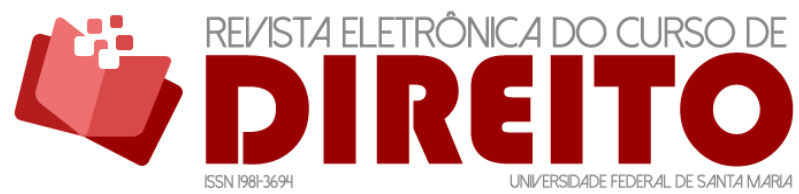

INOVAÇÃO E SUA PRINCIPAL BARREIRA JURÍDICA

Felipe Chiarello De Souza Pinto LARA ROCHA GARCIA

Coalition of Technology Resources for Lawyers (CTRL) e Information Governance Initiative (IGI), “embora o caso de uso varie, o principal aprendizado é que a ciência de dados está se tornando rapidamente parte do procedimento de operação padrão para inovação e resolução de desafios jurídicos"25.

A análise de dados em Direito pode ser utilizada de diversas formas, como na pesquisa de jurisprudência e casos análogos, desfechos de processos, análise de profissionais, governança eletrônica assim como revisão de contratos. De acordo com pesquisa internacional ${ }^{26}$, a análise de dados na prática jurídica tende a crescer esmagadoramente, sendo considerada indispensável em 10 anos.

Nesse sentido, a Lei de Proteção de Dados Pessoais sancionada em 2018 não só será uma fonte de nova atuação para os advogados como também serão eles, escritórios de advocacia, departamentos jurídicos e instituições jurídicas em geral, sejam públicas ou privadas - que precisarão se adaptar.

A figura do Encarregado de Dados (Data Protection Officer), ou Chief of Data Officer, será também necessária no ramo jurídico, transformando os ambientes hoje dominados por egressos das ciências jurídicas, que dividirão a liderança com profissionais de tecnologia.

Veith prevê a necessidade uma transformação na estrutura dos escritórios para a inclusão de novos tipos de profissionais, o que altera não somente o perfil, mas também a hierarquia. A lei que fará com que as empresas busquem a prática jurídica como apoio e

25 "While the use cases vary, the key takeaway is that analytics are fast becoming part of the standard corporate operating procedure for innovation and solving legal challenges".

COALITION OF TECHNOLOGY RESOURCES FOR LAWYERS (CTRL) E INFORMATION GOVERNANCE INITIATIVE (IGI). Data Analytics in Corporate Legal Departments: 2017-2018 Trends. Disponível em: https: / / resources.relativity.com/rs/447-YBT-249/images/CTRL\%20and\%201GI\%20-

\%20Data\%20Analytics\%20in\%20Corporate\%20Legal\%20Departments\%20-\%202017-2018\%20Trends.pdf. Acesso em: 28 jan. 2019.

${ }^{26}$ Original: "Now in its third year, CTRL's Analytics Survey reveals unmistakable traction in the broader adoption of analytics. The overwhelming majority of respondents agree that data analytics will be "will be very important, will be considered indispensable, and [their] use will be widespread" among the legal profession over the next 10 years. As in past years, analytics in eDiscovery continues to lead the way with "95\% of practitioners indicating that their spending in this area will grow or stay level." Additionally, three times as many organizations indicate they will "start using analytics for eDiscovery in the next 12 months." Other ancillary analytics use cases continue to show dramatic year-over-year increased usage rates as well, with massive growth in Outcome Analysis (up 42\%), Information Governance (up 78\%), and Contract Review (up 146\%)."

COALITION OF TECHNOLOGY RESOURCES FOR LAWYERS (CTRL) e INFORMATION GOVERNANCE INITIATIVE (IGI). Data Analytics in Corporate Legal Departments: 2017-2018 Trends. Disponível em: https: / / resources.relativity.com/rs/447-YBT-249/images/CTRL\%20and\%201GI\%20-

\%20Data\%20Analytics\%20in\%20Corporate\%20Legal\%20Departments\%20-\%202017-2018\%20Trends.pdf. Acesso em: 28 jan. 2019. 
ISSN 1981-3694

(DOI): $10.5902 / 1981369441419$

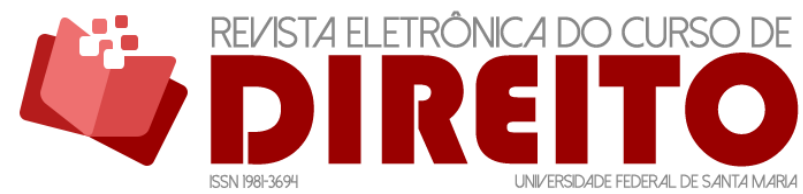

INOVAÇÃO E SUA PRINCIPAL BARREIRA JURÍDICA

Felipe Chiarello De Souza Pinto LARA ROCHA GARCIA

segurança jurídica, também ela vai mudar a forma com que a transformação que a área vive seja objeto da lei.

A figura 6 descreve um ambiente automatizado, com a diminuição de profissionais em início de carreira, jáa que contará com menos trabalhos operacionais. Além disso, um novo profissional será necessário nos escritórios: o gerente de projetos. Ele deverá ser o responsável por unir as áreas jurídica e tecnológica de forma harmônica.

Figura 6: Transformation of Big Law Firms' Organizational Structure ${ }^{27}$

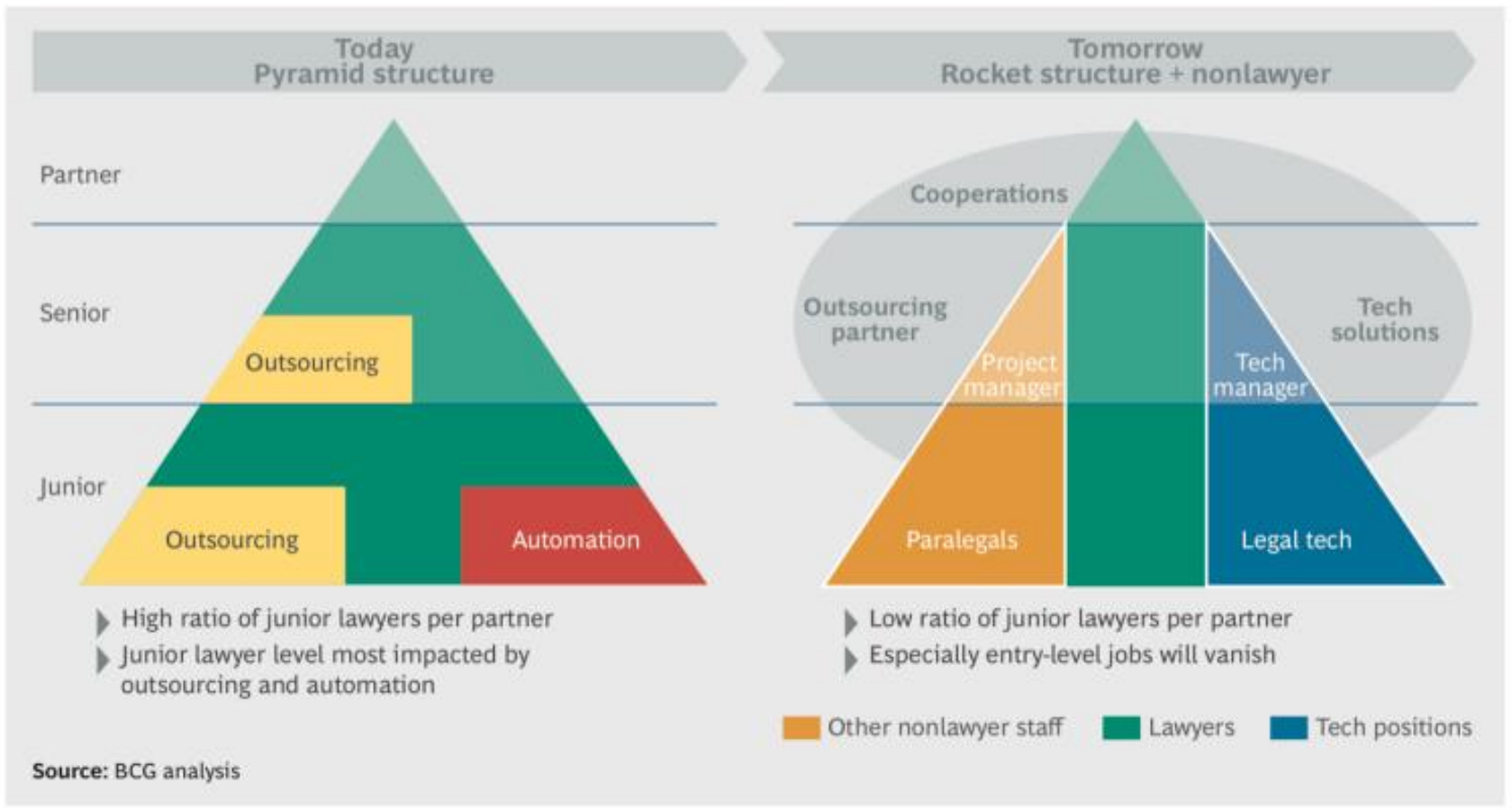

No que tange o relacionamento com o mercado, o modelo de operação será a alterado: o cliente não mais buscará por recomendações jurídicas, mas também por modelos de gestão e eficiência, em uma cadeia de valor descentralizada e automatizada, em que serviços possam ser oferecido em caráter self-service, como na figura 7 de Veith et al.

27 VEITH, C.; BANDLOW, M.; HARNISCH, M., WENZLER, H.; HARTUNG, M.; e HARTUNG, D. How Legal Technology Will Change the Business of Law. The Boston Consulting Group \& Bucerius Law School. Disponível em http://media-publications.bcg.com/How-legal-tech-will-change-business-of-low.pdf. Acesso em: 11 jul. 2020. 
Figura 7: Transformation of Big Law Firms' Business Model ${ }^{28}$

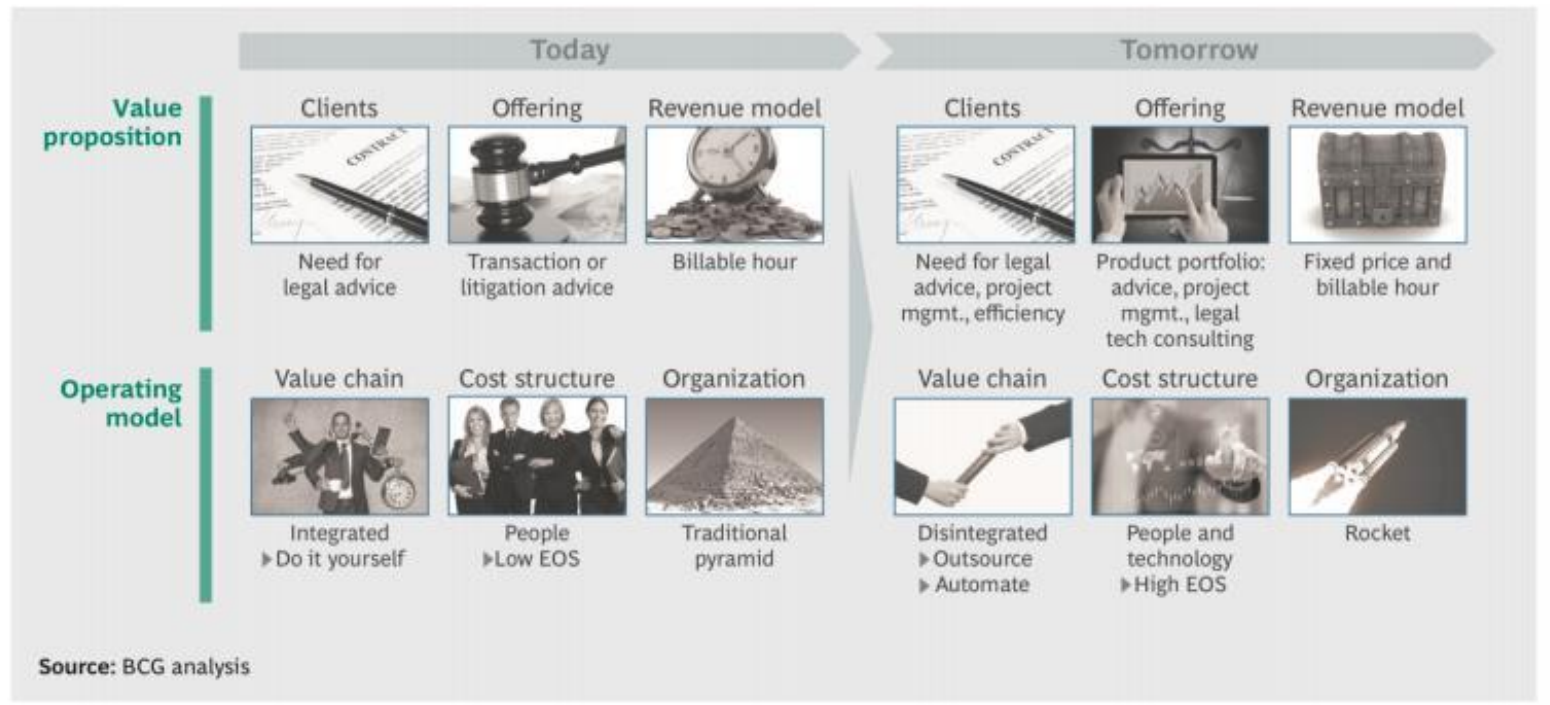

Para José Luis Bolzan de Morais ${ }^{29}$, os impactos produzidos pela "revolução da internet" são pautados, especialmente, pela velocidade destas transformações. A lógica de aceleração das relações, da alteração da forma de trabalho, da automatização dos processos é latente. Em suas palavras: "o mundo percebeu não apenas uma assimetria na capacidade de interceptar e utilizar os dados que circulam pela internet, como também se viu confrontado com as possibilidades daí advindas" 30 .

\section{CONCLUSÃO}

A inovação, como visto ao longo do artigo, pode funcionar como alavanca para o desenvolvimento econômico nacional e relaciona-se com o Direito de duas formas: o utiliza como ferramenta para garantir segurança, Direito da Inovação; assim como modifica a forma com que a prática jurídica acontece, Inovação no Direito.

\footnotetext{
28 Ibidem.

${ }^{29}$ MORAIS, José Luís Bolzan de. O estado de direito “confrontado" pela "revolução da internet”!. Revista Eletrônica do Curso de Direito da UFSM, Santa Maria, RS, v. 13, n. 3, p. 876-903, dez. 2018. ISSN 19813694. Disponível em: https://periodicos.ufsm.br/revistadireito/article/view/33021. Acesso em: 08 abr. 2019. doi: http://dx.doi.org/10.5902/1981369433021 .

$30 \mathrm{Ibidem}$.
} 
ISSN 1981-3694

(DOI): $10.5902 / 1981369441419$

O SNCI descreve o arcabouço jurídico nacional que tem como objetivo prover segurança jurídica a todos os atores do ecossistema de inovação. Seu desafio é acompanhar a velocidade e o dinamismo com que os atores se relacionam.

Este artigo se propôs a descrever e organizar o atual Sistema Nacional de Ciência e Inovação e discutir se ele tem condições de suportar as necessidades da inovação, especialmente no que tange a velocidade, o que impacta, inclusive, nas necessidades da própria prática jurídica como prestação de serviços. O SNCl tem a missão, sob o prisma jurídico, de oferecer alicerce as mudanças que a tecnologia está realizando, embora encontre barreiras como a velocidade e até mesmo a convergência de interesse entre os atores e sujeitos de direito. Desenvolver-se, inovar e estimular o uso da tecnologia para beneficio econômico do pais é a base do Sistema Nacional de Inovação que, a cada diploma, de cunho prático, encontra dificuldades em acompanhar a velocidade das mudanças e das necessidades dos empreendedores, inventores e também dos profissionais de Direito.

Empreendedores, pesquisadores e inventores precisam de estímulo para continuarem inovando. Nesse contexto, a expectativa que esperam ver atendida pelo direito é a garantia de transitarem por um ambiente seguro. Por outro lado, há também limites para o poder econômico, pelos princípios constitucionais que nos regem. No entanto, encontrar o equilíbrio para não travar os avanços, ao passo que também se estimula, não é tarefa fácil. Até porque o próprio Direito, em sua prática jurídica de prestação de serviços, é impactado pela inovação.

Para a Inovação em Direito, o desafio jurídico está em articular todos os atores, que contrastam entre a tradição do setor, seus desafios e o potencial da inovação em ajudar a superá-los.

A prática jurídica, como apresentada ao longo do artigo, além do impacto sofrido pelas tecnologias inovadoras, sofrerá impacto pelos diplomas legais do próprio $\mathrm{SNCl}$, especialmente da LGPD já que a produtividade almejada será oriunda da análise dos dados e da automatização dos processos internos do escritório. Nesse sentido, foi possível entender que compilar selecionar e aplicar os dados no Direito promoverá uma alteração na oferta de produtos, serviços e sistemas tais quais os conhecemos. 0 desafio como juristas, portanto, reside em como nos preparar para o desconhecido a partir de desafios que conhecemos e romper as barreiras que nos impedem de evoluir e contribuir com o desenvolvimento nacional. 
ISSN 1981-3694

(DOI): $10.5902 / 1981369441419$

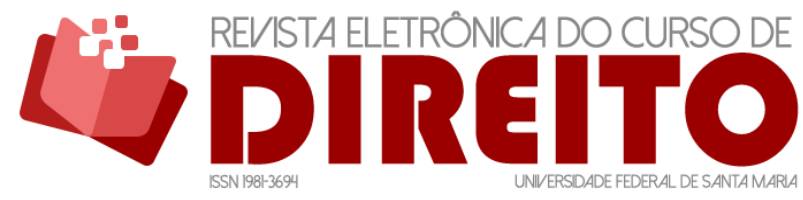

INOVAÇÃO E SUA PRINCIPAL BARREIRA JURÍDICA

Felipe Chiarello De Souza Pinto LARA ROCHA GARCIA

\section{REFERÊNCIAS}

ANDREAE, Zoe.. The Role of Legal Tech Startups in the Digital Transformation of the German Legal Industry. 2016. 78 f. Dissertação (Master of Science in Innovation and Entrepreneurship) Department of Operations, Innovation and Data Sciences, ESADE Business School, Barcelona, 2016. Disponível em: http://dd.lecare.com/legaltech.pdf. Acesso: em 30 dez. 2018.

ASSOCIACÃO NACIONAL DE PESQUISA E DESENVOLVIMENTO DAS EMPRESAS INOVADORAS. Mapa do sistema brasileiro de inovação. In: $14^{a}$ Conferência ANPEI de Inovação Tecnológica, São Paulo, 28 abr. 2014. Disponível em:

http://anpei.org.br/download/Mapa_SBI_Comite_ANPEI_2014_v2.pdf. Acesso em: 11 jul. 2020.

BARBOSA, Denis Borges. Direito da Inovação: Comentários à Lei Federal de Inovação, Incentivos Fiscais à Inovação, Legislação estadual e local, Poder de Compra do Estado (modificações à Lei de Licitações). Rio de Janeiro: Lumen Juris, 2011.

CÉSAR, Daniel; BARRETO JUNIOR, Irineu Francisco. Marco civil da internet e neutralidade da rede: aspectos jurídicos e tecnológicos. Revista Eletrônica do Curso de Direito da UFSM, Santa Maria, RS, v. 12, n. 1, p. 65-88, abr. 2017. ISSN 1981-3694. DOI:

http://dx.doi.org/10.5902/1981369423288. Disponível em:

https://periodicos.ufsm.br/revistadireito/article/view/23288. Acesso em: 20 jul. 2017.

BERCOVICl, Gilberto et al. O Ordenamento da Inovação Tecnológica em Ação: Lei 10.973/04, Lei 11.196/05 e Lei 11.487/07 - Pesquisa Empírica sobre seus Efeitos. São Paulo: Universidade de São Paulo, 2011.

BRAGA, Marco Aurélio Cezarino. Artigos 218 e 219: técnica constitucional para superação do subdesenvolvimento. São Paulo: [s.n], [2007- ].

COALITION OF TECHNOLOGY RESOURCES FOR LAWYERS (CTRL) E INFORMATION GOVERNANCE INITIATIVE (IGI). Data Analytics in Corporate Legal Departments: 2017- 2018 Trends. Disponível em:

https: / / resources.relativity.com/rs/447YBT249/images/CTRL\%20and\%20IGI\%20\%20Data\%20Analyt ics\%20in\%20Corporate\%20Legal\%20Departments\%20-\%202017-2018\%20Trends.pdf Acesso em: 28 jan. 2019.

DEL MASSO, Fabiano; ABRUSIO, Juliana; FLORENCIO FILHO, Marco Aurélio. The Legal Rights Framework for the Internet in Brazil. Disponível em: http://www.legalcurrent.com/the-civilrights-framework-for-the-internet-in-brazil/. Acesso em: 22 nov. 2017.

ETZKOWITZ, Henry e LOET, Leydesdorff. The Dynamics of innovation: from National Systems and 'Model 2' to a Triple Helix of university-industry-government relations. Reserach Policy 29, pgs 109-123, 2000. Disponível em: http://www.oni.uerj.br/media/downloads/1-s2.0S0048733399000554-main.pdf. Acesso em: 07 jul. 2020.

GARCIA, Lara Rocha. Inovação Tecnológica e Direito à Saúde: Aspectos Jurídicos, Econômicos, Tecnológicos e de Políticas Públicas. Curitiba: Juruá, 2017. 
GARCIA, L. R.; SILVA, E.; TERRA, J. C. C. A comparison of telehealth programs between the USA and Brazil: a legal perspective. Dove Press Journal: Smart Homecare Technology and TeleHealth, n. 3, 30 nov. 2015, p. 139-145.

MORAIS, José Luís Bolzan de. O estado de direito "confrontado" pela "revolução da internet”!. Revista Eletrônica do Curso de Direito da UFSM, Santa Maria, RS, v. 13, n. 3, p. 876-903, dez. 2018. ISSN 1981-3694. Disponível em:

https://periodicos.ufsm.br/revistadireito/article/view/33021. Acesso em: 08 abr. 2019. doi: http://dx.doi.org/10.5902/1981369433021 .

ORGANIZAÇ̃̃O DAS NAÇÕES UNIDAS. Objetivos do Desenvolvimento Sustentável. Disponível em: https://nacoesunidas.org/pos2015/ods9/. Acesso em: 15 nov. 2016.

Regulating the internet giants: The world's most valuable resource is no longer oil, but data. THE ECONOMIST. Disponível em: https://www.economist.com/leaders/2017/05/06/the-worldsmost-valuable-resource-is-no-longer-oil-but-data. Acesso em: 20 dez. 2017.

VEITH, C.; BANDLOW, M.; HARNISCH, M., WENZLER, H.; HARTUNG, M.; e HARTUNG, D. How Legal Technology Will Change the Business of Law. The Boston Consulting Group \& Bucerius Law School. Disponível em: http://media-publications.bcg.com/How-legal-tech-will-change-businessof-low.pdf. Acesso em: 11 jul. 2020.

Recebido em: 04.12.2019 / Revisões requeridas em: 21.04.2020 / Aprovado em: 18.06.2020 / Publicado em: 212.07.2020

\section{COMO FAZER REFERÊNCIA AO ARTIGO (ABNT):}

GARCIA, Lara Rocha; PINTO, Felipe Chiarello de Souza. Inovação e sua Principal Barreira Jurídica. Revista Eletrônica do Curso de Direito da UFSM, Santa Maria, RS, v. 15, n. 2, e41419, maio/ago. 2020. ISSN 1981-3694. DOI: http://dx.doi.org/10.5902/1981369441419. Disponível em: https://periodicos.ufsm.br/revistadireito/article/view/41419 Acesso em: dia mês. ano.

Direitos autorais 2020 Revista Eletrônica do Curso de Direito da UFSM

Editores responsáveis: Rafael Santos de Oliveira e Angela Araujo da Silveira Espindola

Esta obra está licenciada com uma Licença Creative Commons Atribuição-NãoComercial-SemDerivações 4.0 Internacional.

\section{SOBRE O/A AUTOR/A}

\section{FELIPE CHIARELLO DE SOUZA PINTO}

Possui mestrado em Direito pela Pontifícia Universidade Católica de São Paulo (2000) e doutorado em Direito pela Pontifícia Universidade Católica de São Paulo (2006). Foi Secretário Municipal de Educação de São Vicente - SP, Membro do Conselho Técnico Científico, do Conselho Superior e do Comitê da Área do Direito da CAPES-MEC, onde Presidiu a Comissão de Classificação de Livros (2010 e 2012 - 2013), Membro da Comissão de Revisão da Matriz Curricular da Graduação em Direito no Brasil (Convidado Externo CNE) (2018) e Diretor da Faculdade de Direito da Universidade Presbiteriana Mackenzie. Atualmente é Pró-Reitor de Pesquisa e Pós-Graduação e Professor Titular da Faculdade de Direito e do Programa de Mestrado e Doutorado em Direito Político e Econômico da Universidade Presbiteriana Mackenzie e Membro da Academia Mackenzista de Letras. Coordenador Adjunto de Programas Acadêmicos da Área de Direito da CAPES-MEC. Membro Pesquisador 2 do CNPq. Membro do Comitê da Área do Direito no Programa SciELO/ FAPESP, Membro do Conselho Editorial da Revista da Procuradoria-Geral do Banco Central e Membro Titular da Academia Paulista de Letras Jurídicas, Parecerista na Área do 
ISSN 1981-3694

(DOI): $10.5902 / 1981369441419$

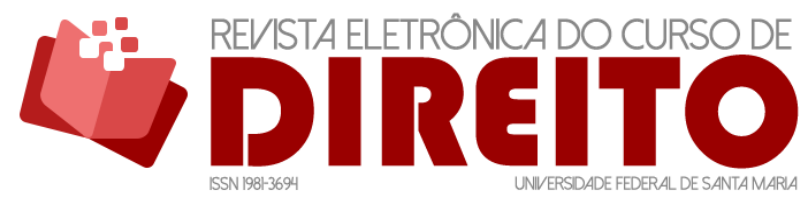

INOVAÇÃO E SUA PRINCIPAL BARREIRA JURÍDICA

Felipe Chiarello De Souza PINTO LARA ROCHA GARCIA

Direito da CAPES-MEC, Professor colaborador do Programa de Pós-graduação em Direito da Universidade de Passo Fundo (UPF). Tem experiência na área de Direito, com ênfase em Direito do Estado, atuando principalmente nos seguintes temas: Direito Administrativo Econômico, Direito Constitucional e Garantias Fundamentais, Ética, Educação e Pesquisa.

\section{LARA ROCHA GARCIA}

Doutoranda em Direito Político e Economico - foco em Inovação e M\&A - Universidade Presbiteriana Mackenzie. Mestre em Direito Político e Econômico - foco em Inovação Tecnológica e Direito à Saúde - Universidade Presbiteriana Mackenzie. Especialista em Inovação e Empreendedorismo - Stanford Business School. Dupla graduação em Direito - Universidade Presbiteriana Mackenzie - e Comunicação Social - UNESP. Autora do livro: "Inovação Tecnológica e Direito à Saúde" pela Editora Juruá. Pesquisadora do Grupo de Pesquisa: "Compliance, Governança Corporativa e Proteção de Dados" - Universidade Presbiteriana Mackenzie. Pesquisadora do Grupo de Pesquisa: "Novas Fronteiras da Ciência Jurídica: Biodireito, Biotecnológico e Inovação" - Universidade Presbiteriana Mackenzie. Pesquisadora na FGVLaw em Direito Empresarial. Membro da Comissão de Direito Digital e Compliance da OAB/SP. Membro da Comissão ICT-Empresa da ANPEI. Membro da Digital Law Academy. Foi fundadora e gerente do Laboratório de Inovação do Hospital Israelita Albert Einstein, assim como liderou a área de Produtos e Inovação do dr.consulta. Professora da Faculdade de Ciências Médicas Albert Einstein 